\title{
LITERATURA Y CULTURA EN LAS FRONTERAS DE LA UTOPÍA
}

ADRIANO CORRALES ARIAS ${ }^{1}$

"Sin duda, los habitantes de este planeta incierto

aún no hemos ejercido nuestro derecho a la locura.”

Rodrigo Quesada Monge

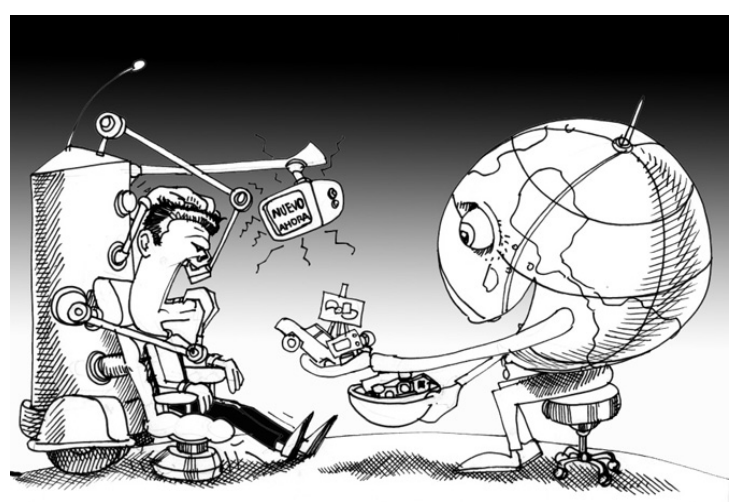

\section{Resumen}

Las siguientes reflexiones me han sido sugeridas, básicamente, por la propuesta del historiador Rodrigo Quesada Monge contenida en su libro Globalización y deshumanización. Dos caras del capitalismo avanzado. Esta obra ha servido de soporte para redondear algunas ideas que he venido rumiando alrededor de las fronteras temporales, geográficas, políticas, económicas, ideológicas y culturales, referidas al quehacer cultural, específicamente artístico y literario, desde este precario presente periférico. Así que debo agradecer el silencioso aporte de don Rodrigo Quesada, quien, sin darse por enterado, me ha convocado a borronear estas cuartillas que, probablemente, al mejor estilo marginal, estén contaminadas de su pensamiento. Claro, los alcances de este ensayo y sus limitaciones son absoluta responsabilidad del "borroneador".

\footnotetext{
${ }^{1}$ Profesor del Instituto Tecnológico de Costa Rica, Sede San Carlos. Escritor, poeta, novelista, Director Revista Fronteras.
} 


\section{PROLEGOMENOS}

Es casi de Perogrullo decir que la obra literaria está inscrita (o previamente escrita) en un lenguaje y que el lenguaje es una creación colectiva no petrificada en su estructura, sino perpetuada en la perenne y renovadora dinámica del habla, el discurso, o en el proceso y el evento de la palabra. Este aserto nos conduce a la comprobación de que la obra literaria no puede ser pensada sin el contexto sociocultural e histórico del que emerge: es lenguaje representativo (simbólico) de su sociedad y de su tiempo, es expresión determinada y determinante. Dicho de otra manera, el lenguaje es un hecho común, por eso las instancias verbales - palabra, proceso, evento, habla, discurso - , 0 discontinuas - innovación, institución, alocución, anonimato, historicidad, eventualidad, virtualidad, edición, etc. - no son patrimonio de ninguna cultura, nación, ideología o raza, sino categorías solidarias y abiertas a la sensibilidad humana.

Otro elemento que, a pesar de poseer una profundidad extraordinaria, puede también parecernos de Perogrullo, es reconocer que el lenguaje humano se expresa mayoritariamente en la oralidad como expresión rítmica y emocional del cuerpo. ¿Qué sucede entonces cuándo la palabra se fija en la escritura ? Pareciera que las palabras escritas carecen de aquélla sensualidad. En la transición de lo oral a lo escrito se pierde, inevitablemente, la gestualidad del emisor o del contertulio. Pero, afortunadamente, con la re-presentación del diálogo se nos coloca de nuevo ante los hablantes de una manera diferente, con una nueva forma de "escuchar" y de "ver": la lectura atenta, la relación íntima con el libro. No sólo está mágicamente presente la sensualidad de la palabra con el recuerdo imaginado del cuerpo que se expresa, sino que se propicia el ejercicio reflexivo de la lengua. Se trata de la conexión entre lo intelectual y lo afectivo, es decir de la unión de nuestro cuerpo a través de la palabra en un ejercicio de memoria vital placentera (Corrales, 2000).

Lo anterior es fundamental en una época de globalización bajo esquema neoliberal (Gallardo,1999:28) donde la transición de lo oral a lo escrito parece desplazarse hacia la imagen tecnológica. A través de la tecnología informática tenemos a nuestro alcance imágenes naturales inaccesibles desde la aldea que, por ello, se globaliza. Pero aunque el mundo ha sido convertido en imágenes, esas imágenes no son exactamente el mundo. Son imágenes que, más allá de su elaborada técnica, no nos mueven al asombro pues carecen de sensualidad. Por lo demás son instantáneas y privilegian un presente pregrabado que desestimula la memoria renunciando a la intimidad e inmediatez de nuestra relación con los objetos y con los demás. Más exactamente: distorsionan precisamente porque privilegian nuestra relación con los objetos humanizándolos, y trastoca la relación con los demás objetivándolos. La imagen virtual "neutraliza" la realidad. Se pervierte entonces la verdadera imagen como un estado interno del ser, parte de su memoria histórica y afectiva, pues una vez más se pierde contacto con nuestro cuerpo, o mejor dicho aún, tanto se insiste en el cuerpo que ya no lo vemos, tal y como sucede en una exposición de arte hiperrealista o más abiertamente en la pornografía (Corrales,2000).

\section{UN NUEVO DIOS:}

\section{EL MERCADO}


Mucho se ha discutido acerca de la globalización, tanto que muchos todavía están sorprendidos por los nuevos paradigmas del capitalismo desarrollado, y otros se han resignado aduciendo que dicho proceso es imparable. Aunque la globalización tiene varias dimensiones de orden cultural, ideológico, económico y político, para aterrizar de inmediato diremos que "es la mejor forma que ha encontrado el sistema capitalista hasta el momento, en su afán por ocultar los verdaderos fundamentos antihumanísticos que lo definen" (Quesada Monge, 1998 :65). Por eso la globalización es un proceso que debe preocupar a hombres y mujeres de letras. En realidad, y según los expertos, la globalización es el mascarón de proa de los teóricos del neoliberalismo que nos recetan la panacea del "mercado perfecto". Dicho en otras palabras, es la ideología que coloca al mercado en el centro de toda relación humana. Por eso están preocupados en desmantelar el Estado-Nación creado por ellos mismos para sus propósitos de acumulación de capital, pues ya no les sirve para el objetivo superior de la mundialización de los negocios. (Acá debo subrayar que para América Latina, paradójicamente, el desmantelamiento del Estado pasa por un reforzamiento del centralismo estatal sobre todo en sus aparatos militares. Por una especie de alquimia neoliberal el milagro consiste en invisibilizar al Estado para fortalecer la represión). Pero además, con la transnacionalización total de la economía y la privatización de las instituciones y empresas públicas, se cierne sobre la población pobre de nuestros países un desamparo absoluto, aunado a una estrategia de desagregación de sus organizaciones tradicionales (sindicatos, cooperativas, partidos, etc.) y despolitización (desideologización) para que no se reorganicen ni se rebelen.

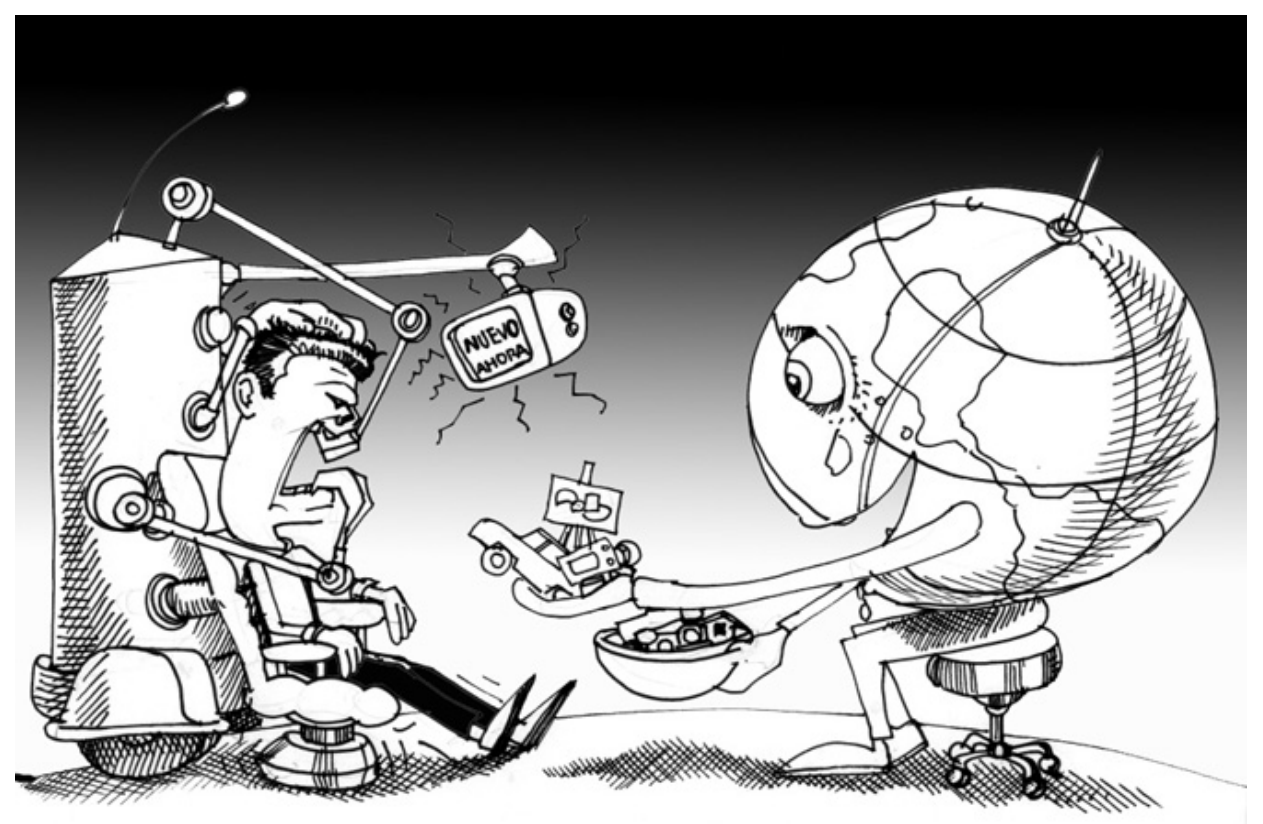

En todo caso se trata, en el nivel económico de precarizar el trabajo (Gallardo, 1991:4), y en el político y cultural de cooptar y crear necesidades de consumo inéditas. "Las personas se reconocen en sus mercancías ; encuentran su alma en su automóvil, en su equipo de alta fidelidad, en su casa a varios niveles, en el equipamiento de su cocina" 
(Marcuse, $1992: 16)$. Pero además se nos ofrece, al Tercer Mundo - léase "Segundo Mundo" excluido sin fronteras y compuesto por los antiguos miembros del "socialismo real" y la mayoría de países de Asia, Africa y América Latina - la panacea del conocimiento a través de la red, a la cual tiene acceso apenas un $10 \%$ de la población mundial (Wing-Ching, 1997), homogeneizando criterios con una cultura masiva que potencia las formas de vida de los principales centros financieros. Es lo que se conoce como la moda y el "conocimiento sin sabiduría" (Quesada Monge, 1998 :72). La competitividad y el consumo son los raseros con los que la globalización mide a los hombres y a los pueblos. Nunca como ahora el rendimiento económico es el que define todos los valores y principios del ser humano en su devenir. Esto es, se humanizan los objetos, por lo tanto son más importantes que las personas a las cuales se les percibe solamente como consumidoras y productoras de objetos, lo que genera un alto nivel de fragmentación y de caos social que legitima la ley de "sálvese quien pueda". Para nuestros países esto significa que los pobres habrán de convertirse en "informales" o, peor aún, en "deshechables" (Gallardo, 1991 :4). Es el sacrifico que debemos rendir ante el altar del nuevo dios: el omnipotente mercado.

Por eso para nosotros, centroamericanos en las fronteras de un milenio, la lectura de la globalización debe pasar por el hecho de que nuestros países, con la caída del socialismo real y el supuesto fin de la "guerra fría" ( que en nuestra historia reciente fue mucho más que caliente), se han vuelto más vulnerables aún a la competencia. Por lo demás se han abierto nuevos polos de desarrollo y nuevas periferias, es decir se han trastocado las fronteras, las cuales, incluso al interior de nuestros pequeños países, concentran riqueza en pocas manos y excluyen aún más a grandes mayorías. La homogeneización, paradójicamente, implica polarización y conflicto social.

\section{¿MODERNOS O POSTMODERNOS ?}

Podríamos afirmar, con muchos autores, que para América y los americanos, la globalización se inició con la llegada de los europeos en 1492. Para el caso de América Latina, luego de la Conquista, la Colonia se "trasladó" en el tiempo, en algunos casos hasta nuestros días, pues las rebeliones de la independencia, al contrario de las revoluciones burguesas en Europa, fueron lidereadas por las aristocracias terratenientes con un criterio conservador. Por eso el marco económico y sociocultural de nuestros países soportó pocos cambios hasta las Reformas Liberales a mediados del siglo XIX, las cuales en algunos casos no pasaron de ser cosméticas. La modernidad es tardía en Latinoamérica, tanto que no hemos salido de ella cuando ya nos proponen una postmodernidad que todavía no acabamos de digerir. Nuestra modernidad se muerde incesantemente la cola.

Lo anterior traía aparejado un modelo cultural "civilizatorio" hegemonizado por las características coloniales. "La 'civilización' de los americanos, en sus aspectos culturales, está enmarcada en la imposición del aprendizaje de una lengua con connotaciones de prestigio y cristiandad: el español. La aculturación lingüística fundamenta las bases para la pérdida de la identidad cultural de los americanos e inmigrantes traídos como fuerzas productivas, pero afianza la relación de poder de los colonizadores". (Pochet, 1996 :30). De esa manera la confrontación de los europeos con los nativos conlleva, además del genocidio, la imposición, a través de la lengua, de una ideología de subordinación, con claras tendencias colonialistas: todo lo equivalente a lo "blanco" o europeo - más tarde estadounidense - es lo bueno y positivo, en tanto lo relacionado con lo negro, mestizo u 
obscuro es sinónimo de maldad y negatividad (Pizarro, 1985 :15). Es la herencia colonial "tradición centralista" la llama Rodrigo Quesada, parafraseando al autor Claudio Véliz, y refiriéndose al ejercicio del poder bajo un estilo burocrático y autoritario (Quesada Monge, 1998:160-161) - que nos unifica en torno a una cultura de la dependencia que simplemente ha venido cambiando de metrópolis, y que, por lo tanto, posee un alto contenido totalitario. Por eso la participación popular o civil en los procesos de conformación de los Estados Nacionales y sus políticas de homogeneización, se ha expresado, las más de las veces, como batallones de combatientes descalzos o masas manipuladas electoralmente.

No obstante, nuestro continente ha transitado todos estos siglos de hegemonía colonial, neocolonial e imperialista, en una búsqueda constante de su verdadera identidad. La base de esa búsqueda es un cúmulo de contradicciones históricas, políticas, sociales, estéticas y lingüísticas, que la homogeneización del imaginario lineal y oficial impuesto por las lecturas metropolitanas ha obviado, y que ni la modernidad ni la postmodenidad han resuelto. En esa búsqueda nos hemos ido dado cuenta que Latinoamérica no solamente habla español, también se comunica en portugués, inglés, francés, y sus variantes como el creole, el patúa o el papiamento, y además en chino mandarín o cantonés, y por supuesto en las ancestrales lenguas como el quechua, el nahuatl, o el bribrí, solo para mencionar algunas. Pero además entendimos que muchos colores, sabores, olores, sensaciones y eclosiones telúricas, así como danzas e instrumentos musicales, se designan con vocablos provenientes del bantú 0 del yoruba. Nos descubrimos pluriculturales y multilingües. El sincretismo se posesionó antes que la postmodernidad tratara de cerrarnos la ventana para derribar las puertas. De ese sincretismo y de esos diferentes espacios culturales surge una extraordinaria diversidad literaria y hasta una literatura multilingüe.

\section{DESHUMANIZACIÓN Y TRANSNACIONALIZACIÓN DE LA CULTURA}

Para sobrepasar lo evidente en el discurso, insistiré en este apartado, al igual que muchos poetas y artistas, en ir más allá de las palabras: Estamos en crisis, tanto de identidades como de instituciones. Sin embargo la burguesía, clase social diseñadora del capitalismo, ha sabido ingeniárselas con las crisis periódicas del sistema. Para los griegos estar en crisis era positivo porque significaba que podíamos mejorar, individualmente claro está. Pero la burguesía y el capitalismo convirtieron las crisis en traumas sociales; las necesidades ahora son colectivas. Así la modernidad se caracterizará por entrar en crisis. Se es moderno en tanto la crisis me obligue a escaparme hacia el futuro en alas del progreso y la razón. El intelectual moderno es aquél que maneja las coordenadas espacio temporales que le permiten avizorar un futuro mejor sin parar mientes en destrozar el presente, y sin necesidad de evocar un pasado mítico.

"Al cuantificar con tanta meticulosidad la jornada laboral, la burguesía acercó el concepto de valor-trabajo al presente y lo vació de pasado. Así, logró que el presente y el futuro se volvieran las categorías mediante las cuales la burguesía sustancializaba la temporalidad de la producción. Por eso, bien se puede sostener que las vanguardias (artísticas o políticas), las que ponen con tanta claridad su énfasis metodológico y técnico en el mañana, articulan una noción de futuro que está íntimamente integrada a la instrumentalización que puede hacerse de las nociones de modernidad y progreso" 
(Quesada Monge, 1998: 75). Esta larga cita me sirve, no solo para contextualizar las razones ideológicas de la vanguardia y la postvanguardia, (que casi siempre fueron contestarias, pero también reaccionarias caso del futurismo, o el dadaísmo) sino, sobre todo, para cotejar las recurrentes "crisis" del artista y el escritor. La angustia y la ansiedad son las dos caras de la misma moneda crítica del creador moderno que cree en el progreso y en el futuro, así como en sus posibilidades expresivas para acercar ese futuro a su caótico presente. El, o ella, a pesar de su precariedad existencial o material, y de su conciencia marginal, se saben poseedores de un don que les permite trascender un presente cargado de mediocridad e incomprensión. Son vanguardistas iluminados por el porvenir. Esa condición (que no postmoderna) la sintetiza muy bien un verso célebre del poeta español Gabriel Celaya: "La poesía es un arma cargada de futuro".

De esa manera el creador artístico se evade de un presente plagado de condiciones antihumanas y se convierte en un "desadaptado" (en el sentido actual de no estar globalizado). Esa evasión, o ese escapismo, se puede dar en dos vías: La primera es la evasión propiamente, la cual se aleja de una realidad cruel o espantosa pero sin esperanza (Franz Kafka y el grueso de su obra). La segunda contiene a la esperanza como componente de la utopía y puede convertirse en ensoñación creadora (Bloch, Ernst, 1993 :53-54). Esta última hace que los sueños sean posibles, al menos en la concreción de la imagen artística, independientemente de que la misma se exprese a través de la palabra, la nota musical, el color, el volumen o la textura. Así la vigilia cobra sentido, la Vigilia en pie de muerte, tal y como plantea el célebre poemario de nuestro poeta Isaac Felipe Azofeifa. En otras palabras, la esperanza se encarna en el lenguaje artístico adquiriendo un poder plurisignificativo.

A pesar de ello la burguesía, por medio de su amplia lucidez para convertir en mercancía todo lo que toca, se percata muy bien de ese "empoderamiento" del objeto y del lenguaje artístico, y lo coopta a través de las múltiples posibilidades del mercado: la obra artística se sacraliza en el museo o se "esconde" en las galerías o colecciones privadas (esto último torna paradójico el poder mercantil de la burguesía: la obra se compra no para ser exhibida, sino para guardarla en los sótanos de un banco como inversión que produce plusvalía, por ejemplo la obra maestra de Vincent Van Gogh "Retrato del Dr. Gachet" perdida en la oscuridad de algún coleccionista en Nueva York, Suiza o Francia, luego de alcanzar la astronómica suma de \$82 millones); las Bienales y los Certámenes se trastocan con la promoción de nombres y apellidos en premiaciones carentes de rigor estético; y la "obra literaria" se convierte en un "boom" editorial transnacional. Se privilegian las historias livianas en ambientes edulcurantes o exóticos y se pervierten las palabras en un juego insulso que algunos llaman postmoderno, pero que vacía a la literatura de sus esencias poéticas. Los libros se convierten en mercancías circulando en un mercado cultural masivo y cargado de publicidad espúrea. El escritor se convierte en un escribidor a destajo y las grandes editoriales le dictan, a través de un contrato, los temas y formas preferidas del gran público. El best seller se re-produce (¿deconstruye ?) y se hace circular con las técnicas más avanzadas de la mercadotecnia, incluso virtualmente, mientras las obras artísticas son subastadas por marchantes convertidos en altos ejecutivos.

Por otra parte el sistema globalizado nos birla, además de nuestro derecho al goce estético, el derecho al goce de nuestros cuerpos, porque el amor, la amistad y la solidaridad son peligrosos. Los sentimientos asociados al erotismo y al placer sexual son subversivos. Como bien apunta Rodrigo Quesada, "el amor y la amistad han perdido cuerpo, porque la cultura burguesa ha hecho todo el esfuerzo posible por hacer aparecer 
a la personalidad productiva como un pecado"(Quesada Monge, 1998:79-80). Debemos escondernos para hacer el amor, o adaptarnos al eros virtual a través de la red. De allí nuestra postmoderna y colectiva soledad. Pero a la vez, se decreta, con la "muerte de la historia" (Fukuyama,1992), la imposibilidad ya no solo de soñar, sino de recordar. El olvido es la practica constante que se nos recomienda, tanto en términos históricos como estéticos. Así como se nos despoja de nuestro trabajo también se nos despoja del patrimonio de la memoria individual y colectiva y de nuestra capacidad de soñar. El pasado ya no existe a no ser como un conjunto de hechos idos y desconectados de nosotros, es un eterno presente de producción y consumo desarticulado por la imagen tecnológica. El mundo se reconfigura como un espacio hostil donde el individuo ya no posee las claves para reconocerse con los demás, ni para entender el origen de la violencia estructural. Está solo, triste y abandonado. La homogeneización deshumanizada de la cultura pretende, entre otras cosas, borrar la memoria y los sueños históricos de los pueblos periféricos, así como los traumas causados por el mismo sistema: El Ché Guevara es una camiseta, no un pensador/combatiente antiimperialista; Vietnam es una metáfora bélica, no la estruendosa derrota del imperio.

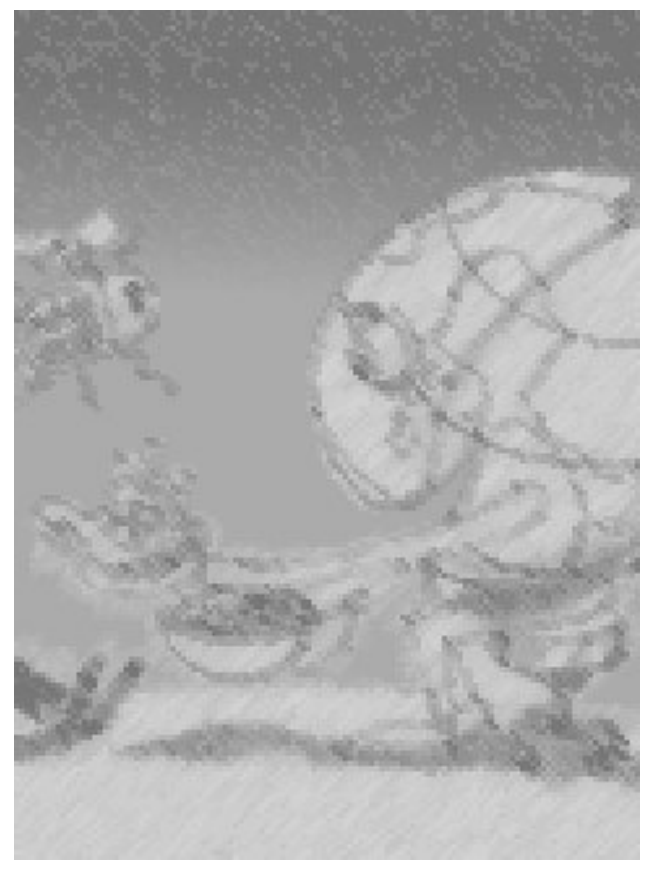

Aquí es cuando el verdadero artista entra en crisis y se escapa. Pero la validez de su escape dependerá de la manera en que socialice su crisis personal. El imperativo de esa crisis será entonces comunicarse a toda costa, mejor dicho escribir, pintar, esculpir, componer, para lograr que su “Grito, luego existo", dolorosa y lúcida posición del genial escritor cubano Reynaldo Arenas, cobre sentido social. He ahí el único compromiso del creador: comunicar estéticamente el dolor, la tragedia, su crisis existencial, pero también la esperanza y la alegría de vivir, a los otros, desde su trabajo cotidiano con las formas artísticas. Para el escritor ese compromiso pasa por el riguroso afinamiento de las palabras. No basta solamente con evocar el objeto, el cual - contrario a lo que parece proponer el escritor salvadoreño Rafael Menjívar (Menjívar, 2000 :30-38) - tiene su propia historia a pesar de las palabras, pero adquiere sentido en la "mirada" del sujeto y en su acción transformadora a través del dinámico evento de la palabra. Pero ese compromiso debe ir más allá, como ciudadano de su patria y del mundo, debe asumir el gran reto que 
nos ha lanzado la mal llamada postmodernidad con su asepsia ideológica y su laxa visión histórico-social: "desmercantilizar" el arte y la literatura para delimitar el espacio de la deshumanización de la cultura a través de la transnacionalización del capital.

\section{CONCLUSIONES}

"Controlar la vida privada de las personas, diseñar sus sueños y condicionar sus utopías, sería el triunfo más logrado de los ideólogos de la globalización" (Quesada Monge, 1998:202). Esto quiere decir que la amistad, la solidaridad, la memoria colectiva e individual, la paz, el amor, la ensoñación creadora, en fin, la vida, son la respuesta que nuestros pueblos globalizados deben enarbolar para no sucumbir ante el tremendismo neoliberal que plantea una única salida capitalista plagada de frustración deshumanizada, sea de necrofilia. Dentro de esa perspectiva proponemos las siguientes ideas como fundamentos de una respuesta digna del artista y del escritor ante la modificación de las políticas culturales en América Latina:

1. En primera instancia, como plantea Rodrigo Quesada, debemos proponernos la recuperación de ese espacio esencial que la burguesía y el capital aún no conquistan totalmente: la posibilidad del diálogo personal con el otro.

2. Recuperar nuestros cuerpos como entes soberanos, como geografía de nuestra verdadera patria espiritual. En el amor y en el placer erótico (el eros como disfrute límite del otro), así como en nuestra privacidad dialogante, reside nuestra más clara resistencia de humanos comprometidos con la vida. Solamente de esa manera podremos superar la soledad y la atomización postmodernas, y reivindicar la palabra como un instrumento orgánico de nuestra verdadera humanidad.

3. Destacar nuestra riqueza pluricultural, multiétnica y multilingüe, así como sus intensas posibilidades de sincretismo, hibridación y mixtura de géneros.

4. Fortalecer el ejercicio de la memoria, tanto individual como colectiva, para darle continuidad a nuestros sueños. Esto significa resemantizar (recrear) nuestras historias con la capacidad transformadora de la imagen artística y la palabra compartida.

5. Reivindicar la sensualidad y la espontaneidad como factores inherentes a nuestra capacidad de vida. De esa manera el ocio creativo, la "locura" de sabernos vivos frente a la cordura necrófila del sistema, el humor, la sátira y el sarcasmo, son la puerta grande por donde salimos a protestar contra el orden caótico de la productividad y la cosificación de la realidad.

6. Recuperar los espacios públicos y los puntos de encuentro como plazas, parques, calles, bulevares, tabernas, cafés, burdeles, y descampados, para proponer la fiesta y el carnaval de la convivencia solidaria con los demás, como una forma de amistad y comunicación alternativa, pero también de defensa comunitaria.

7. Finalmente se trata de construir y desarollar redes alternativas de intercambio y producción de nuevas formas y experiencias artísticas. Para "desmercantilizar" el arte 
no basta con buenas intenciones ni manifiestos, debemos entablar el diálogo con otros creadores y abrir las fronteras de la creatividad para potenciar producciones compartidas o distribuir "de otra manera" las nuestras. Ir al encuentro con los otros. En otras palabras, debemos oponer a la globalización homogeneizante el amor, la amistad, los sueños y la poesía desde nuestras propias posibilidades creadoras y comunales, no solo en la producción, sino también en la difusión y en la circulación de los bienes culturales.

San Carlos-San José, octubre-noviembre del 2000.

\section{BIBLIOGRAFÍA CONSULTADA}

Bloch, Ernst: "La utopía como dimensión y horizonte de su pensamiento. Antología, documentación y estudios". (Citado por Quesada Monge, Rodrigo en Globalización y deshumanización. Dos caras del capitalismo avanzado). En Revista Anthropos No. 41 1993, Editorial El Hombre, Barcelona.

Corrales Arias, Adriano: “La Literatura Andariega” en Suplemento Cultural Áncora del periódico La Nación, 4 de junio del 2000, San José.

Gallardo, Helio: "Notas para contribuir a una discusión sobre los nuevos actores sociales” en Revista Pasos No. 36, julio-agosto 1991. DEI, San José.

Azul, San José, 1999.

Globalización, lucha social, Derechos Humanos. Ediciones Perro

Marcuse, Herbert: El Hombre Unidimensional. Ensayo sobra la Ideología de la Sociedad Industrial Avanzada. (Citado por Quesada Monge, Rodrigo en Globalización y deshumanización. Dos caras el capitalismo avanzado). Joaquín Mortiz, México, 1992.

Menjívar Ochoa, Rafael: “El objeto y sus palabras” en Revista Fronteras No. 8, segundo semestre 2000, Instituto Tecnológico de Costa Rica, San Carlos.

Pochet, Lina: “América Latina y el Caribe: sincretismo base para una nueva historia literaria" en Revista Reflexiones No. 51 octubre 1996, Universidad de Costa Rica, San José.

Pizarro, Ana: “La literatura latinoamericana como proceso". Centro Editor de América Latina. Buenos Aires, 1985. (Citada por Lina Pochet).

Quesada Monge, Rodrigo: Globalización y deshumanización. Dos caras del capitalismo avanzado. Editorial de la Universidad Nacional, Heredia, 1998.

Wing-Ching, Isabel: Conferencia dictada en la Sede Regional del ITCR en San Carlos, 1997. 